\title{
Indices for the Betterment of the Public
}

\author{
Vincent Charles $^{1}$, Ali Emrouznejad ${ }^{2 *}$, Michael P. Johnson ${ }^{3}$ \\ ${ }^{1}$ School of Management, University of Bradford, UK \\ ${ }^{2}$ Aston Business School, Aston University, UK \\ ${ }^{3}$ McCormack Graduate School of Policy and Global Studies, University of Massachusetts, Boston, USA
}

Over the years, the quest for a better society has led to the birth of a variety of composite indices of development, from the gross domestic product to the happiness index. These indices usually integrate various social, cultural, psychological, and political aspects and are considered of vital importance for evaluating a country's level of development and for assessing the impact of policy especially in the public sector. Overall, they consist of numerical measures that describe the well-being of both the individual and the society as a whole.

This Special Issue on Indices for the Betterment of the Public of Socio-Economic Planning Sciences includes thirteen research articles by authors from Belgium, Colombia, Greece, India, Iran, Italy, Peru, Portugal, Spain, and the United Kingdom. It spans a spectrum of research areas, addressing measures such as: human development, social progress, regional economic resilience, happiness and well-being, education quality, and corporate governance.

The first two papers focus on the Better Life Index (BLI), which was developed by the OECD as a response to the increasing view that Gross Domestic Product is a limited tool to measure societal well-being. In the paper titled "Measuring well-being by a multidimensional spatial model in OECD Better Life Index framework", Salvatore Greco, Alessio Ishizaka, Giuliano Resce, and Gianpiero Torrisi explore the role played by the distance between societal priorities and country-level performance in Better Life Index, as well as in multidimensional well-being. Building upon the OECD's survey of the user weightings related to 11 different topics, the authors interpret the country-level citizens' individual weightings as the optimal subjective mix of well-being and interpret the country-level values of the topics as the mix of well-being provided by policymakers. Results indicate that the societal loss at country-level is negatively related to the overall well-being and the main indices of quality of democracy.

\footnotetext{
${ }^{*}$ Corresponding Author: Ali Emrouznejad, Professor of Business Analytics, Aston Business School, Aston University, Birmingham, UK, E-mail: a.emrouznejad@aston.ac.uk, Website: http://www.Emrouznejad.com
} 
The next paper by Gregory Koronakos, Yiannis Smirlis, Dimitris Sotiros, and Dimitris K. Despotis, titled "Assessment of OECD Better Life Index by Incorporating Public Opinion", introduces a novel methodology for the assessment of the OECD's Better Life Index by means of a hierarchical bottom-up procedure for the aggregation of the components of each level of the BLI. Public opinions about well-being are also incorporated into the assessment models in the form of weight restrictions. The authors then apply the proposed approach to the data of 38 countries (35 OECD and 3 Non-OECD economies) for the year 2017. The approach can be utilized for aiding the design of policies via well-being measurement or as a policy assessment framework.

The following four papers address various aspects related to the Human Development Index (HDI). Along with the Better Life Index, the Human Development Index is commonly used by policymakers and other interested parties to gain a better view of their societies' development level; nevertheless, this index suffers from methodological shortcomings and critiques. In the paper titled "A New Approach Based on BWM and MULTIMOORA Methods for Calculating Semi-Human Development Index: An Application for Provinces of Iran”, Hashem Omrani, Arash Alizadeh, and Mohaddeseh Amini propose a new approach wherein they incorporate policymakers' preferences in the calculation of semi-HDI using the Best Worst Method. Then, MULTIMOORA method is applied to rank the provinces. A set of new criteria are also defined in two dimensions of healthy life and population education.

In the paper titled "Constructing Composite Indicators with Shannon Entropy: The Case of Human Development Index”, Roxani Karagiannis and Giannis Karagiannis further propose a weighting scheme for constructing composite indicators based on Shannon entropy. More specifically, Shannon entropy is used to derive a set of common (but not necessarily equal) weights. The authors then explore the potential of the proposed weighting scheme empirically by re-estimating the HDI for 2012, which in UNDP (2013) publications is obtained using equal weights.

Then, in the paper titled “Comparing Regional Human Development using Global Frontier Difference Indices", Tom Van Puyenbroeck and Nicky Rogge use variants of the global frontier difference index, combined with the 'benefit-of-the-doubt' approach to composite indicator construction, to study inter-regional differences in human development performance. The authors further apply their approach to regional categories of countries in the construction of the HDI. 
Finally, the paper titled "Constructing a Generalized Model of the Human Development Index”, by B. K. Mangaraj and Upali Aparajita critiques the current formulation of the HDI that uses fixed 'goalposts' that represent maximum common aspiration levels of all human development indices as one that penalizes un-balanced or skewed development across HD dimensions and does not measure the shortfall in achievement of HD targets. The authors instead propose a generalized HDI that accounts for both the 'attainment' and 'shortfall' perspectives of individual HD measures, as well as a relative generalized HDI that assesses the relative performance of countries with respect to a benchmark country that may change for each year that this index is computed. The authors perform analyses that support their choice of new HDI measures, and conclude that generalized HDI scores can allow the classification of countries into three levels based on whether one, two, or three relative values of component indices are negative, and make recommendations that countries should focus their development efforts on the most negative dimension to the least negative dimension.

In time, various indices have been used to measure social progress; despite this, the search for better measures has never ceased. In the paper titled "An envelopment-based approach to measuring regional social progress", Vincent Charles and Fernando A. D'Alessio propose a method to measure social progress at the sub-national level, with an application to the Peruvian regions. To this aim, the authors build a unified envelopment-based model for integrating a two-stage process of the index generation. The paper represents a contribution to the practical measurement of social progress and should be of interest to policymakers concerned with proposing policies of social investment that create the conditions for all individuals in the society to reach their full potential.

The capacity of regions to cope and react to exogenous forces, that is, their resilience capacity, is an important item on national agendas. Nevertheless, definitions of resilience has generally relied on a single dimension; missing is a more comprehensive or systematic view of this concept. In the paper titled "A composite policy tool to measure territorial resilience capacity", Nicola Pontarollo and Carolina Serpieri propose a composite regional economic resilience indicator, which they apply to identify the differentiated responses to the negative shock due to the 2008 economic crisis in the EU. Among others, the results show that national resilience trends dominate in the EU-15, while in the EU-13, a more heterogeneous spatial pattern is apparent. The paper should be of interest to policymakers interested in monitoring regional resilience and targeting territorially integrated policy interventions. 
Happiness economics can provide us with valuable insights about how people make choices and how much happiness these choices bring to one's life. In the paper titled "Which formula for national happiness?", Chris Tofallis proposes a model of happiness which is multiplicative rather than additive; this model provides a better fit to the data in the World Happiness Report and is therefore superior in its explanatory power. As the proposed model provides a better grasp of how changes in the explanatory factors affect national happiness, this paper should be of interest to policymakers and practitioners concerned with identifying which factors to focus on.

Education has a direct effect on the economic growth and well-being of a nation, which is why improving the quality of education has been a priority on governmental agendas around the world. In the paper titled "Evaluating the Global Efficiency of Teachers through a Multicriteria Approach", Mariano Luque, Oscar Marcenaro-Gutierrez, and Ana Belen Ruiz study the efficiency of primary education teachers according to a set of three synthetic indexes which are built using multi-criteria optimization techniques. The authors use data from PIRLS (Progress in International Reading Literacy Study) and TIMSS (Trends in Mathematics and Science Study) for fourth-grade reading, mathematics and science teachers in Spain. The analysis performed contributes to a better understanding of the policies to be followed in order to promote efficiency in teaching.

Generally, socioeconomic indices try to represent the welfare or well-being of populations and fail to capture the "gravitational attraction" of locations. In the paper titled "Closeness matters. Spatial autocorrelation and relationship between socioeconomic indices and distance to departmental Colombian capitals", Alejandro Builes-Jaramillo and Laura Lotero apply a geo-statistical test to analyse spatial autocorrelation and clusters of three socioeconomic indices (living conditions, multidimensional poverty, and unsatisfied basic needs) in Colombia and to explore the relation of the identified clusters with their physical distance from departmental capitals. Among others, their study shows how proximity to departmental capitals does not explain—nor is it sufficient to enhance—-socioeconomic conditions.

We now turn to papers that explore measures of well-being that bring together social concerns that reflect quality-of-life issues for residents and the quality of life, one might say, of businesses. In the paper titled "A Critique on the Corruption Perceptions Index: An Interdisciplinary Approach”, Pornanong Budsaratragoon and Boonlert Jitmaneeroj introduce an assessment of the index of national well-being, the Corruption Perceptions Index (CPI). The 
CPI, defined as a function of indicators measuring subjective perceptions of the prevalence of corruption, or "abuse of entrusted power for private gain", is computed in practice as the sum of indicators from 12 respected non-profit organizations. Using four analytic methods from machine learning and business management, the authors demonstrate that individual data sources have unequal impacts on the CPI, that there exist causal interrelations between the CPI's data sources, and that the levels of corruption perception appear to be related to the levels of economic development, with developed countries exhibiting lower perceived corruption than emerging countries. The authors provide multiple policy recommendations that may significantly change the way that government and non-profit analysts use measures like the CPI. From benchmarking the scores of CPI components across clusters of countries that share common values of CPI component indicators, to recommending that policymakers address multiple data sources for the CPI as opposed to single data sources or an aggregation of equallyweighted data sources, to proposing a modified CPI that excludes insignificant data sources, the authors demonstrate convincingly that advanced analytic methods have the ability to greatly change the way that an index of quality of life associated with the business environment is computed and used.

The importance of good governance in banking firms has received significant attention in recent years; however, the empirical works on the quantification of corporate governance for banking firms are very limited. In the final paper of this special issue titled "A non-parametric index of corporate governance in the banking industry: An application to Indian data", Rachita Gulati, Ruth Kattumuri, and Sunil Kumar present a methodological framework for constructing a non-parametric corporate governance index for banks using a 'benefit-of-thedoubt' approach. The approach is then applied to a data set of 40 Indian banks operating in the year 2017. The proposed corporate governance index should be useful to policymakers and regulators as a handy tool for examining the differences in the levels of governance compliance across banks.

The many academics and researchers who contributed articles and the experts within the field who reviewed the articles have made this Special Issue on Indices for the Betterment of the Public of Socio-Economic Planning Sciences possible. We wish you, our readers, informative reading! 


\section{Biography of authors:}

Vincent Charles is currently associated with the School of Management, University of Bradford ; previously, he was with Buckingham Business School, University of Buckingham, as a Professor of Management Science and Director of Research. He is a postdoctoral research fellow in maritime studies from National University of Singapore, Singapore. He is an Honorary Professor at Maastricht School of Management, The Netherlands; an Affiliated Distinguished Research Professor at CENTRUM GBS (accredited by AACSB, EQUIS, and AMBA), PUCP, Peru; a Fellow of the Pan-Pacific Business Association, USA; a Council Member of the Global Urban Competitiveness Project, USA; and a Higher Education Teaching and Learning Association Liaison to Peru, HETL USA. He holds Executive Certificates from the MIT Sloan School of Management (USA), Harvard Business School (USA), and IE Business School (Spain). He has more than 20 years of teaching, research, and consultancy experience in various countries and has published over 120 research outputs. He is a recipient of many international academic honours and awards. He has developed the $4^{\wedge} 3$ Architecture for Service Innovation. He has published books with SpringerVerlag, Pearson Education, Cengage, and Cambridge Scholars Publishing, UK. His areas of focus are Performance Measurement and Management (Productivity, Quality, Efficiency, Effectiveness); [Big] Data Science; Competitiveness; Social Progress; Doing Business; Innovation; and Design Thinking.

Ali Emrouznejad is a Professor and Chair in Business Analytics at Aston Business School, UK. His areas of research interest include data mining and big data as well as mathematical modeling for performance measurement and management. He holds an MSc in applied mathematics and received his $\mathrm{PhD}$ in operational research and information systems from Warwick Business School, UK. Dr Emrouznejad is Editor / guest Editor or Associate Editor in several top ranked journals including: Annals of Operations Research, European Journal of Operational Research, Socio Economic Planning Science and several others. He has published over 160 articles in top ranked journals. Dr Emrouznejad is author / editor of several books including (1) "Applied Operational Research with SAS" (CRC Taylor \& Francis), (2) “Big Data Optimization" (Springer), (3) "Performance Measurement with Fuzzy Data Envelopment Analysis" (Springer), (4) "Big Data for the Greater Good" (Springer), (5) "Managing Service Productivity" (Springer), (6) "Fuzzy Analytics Hierarchy Process" (CRC Taylor \& Francis), and (6) "Handbook of Research on Strategic Performance Management and Measurement" (IGI Global). For more information see: www.Emrouznejad.com.

Michael P. Johnson is Professor and Chair of the Department of Public Policy and Public Affairs at University of Massachusetts Boston. Dr. Johnson's research focuses on developing decision models and decision support systems to improve operations and strategy design of nonprofit organizations and government agencies. His primary application focus is on affordable and assisted housing, community development, climate change response, and public services. Dr. Johnson has published widely in academic journals of decision science, urban planning, and housing policy. His most recent extended works include a co-edited volume of papers on diversity, equity and inclusion titled INFORMS Editor's Cut: Diversity and Inclusion: Analytics for Social Impact (INFORMS, 2019), a lead-edited special issue of European Journal of Operational Research on community operational research (Elsevier, 2018) and a lead-authored book, Decision Science for Housing and Community Development: Localized and Evidence-Based Responses to Distressed Housing and Blighted Communities (Wiley, 2016). Dr. Johnson earned his $\mathrm{PhD}$ from Northwestern University in operations research in 1997 and his bachelor of science from Morehouse College in 1987. 